\title{
Los mercaderes en las jácaras de Quevedo
}

\section{The Merchants in Quevedo's Jácaras}

\section{Emmanuel Marigno Vazquez}

Université de Lyon/Saint Etienne

FRANCIA

emmanuel.marigno@univ-st-etienne.fr

[Hipogrifo, (issn: 2328-1308), Volumen extraordinario, 1, 2018, pp. 233-243]

Recibido: 30-05-2017 / Aceptado: 08-06-2017

DOI: http://dx.doi.org/10.13035/H.2018.extra01.16

Resumen. Intento aquí poner de realce la originalidad de la figura del mercader en las jácaras de Quevedo. Hago primero hincapié en consideraciones lexicológicas y acerca de los vínculos humanos que presupone este poder mercantil; se estudia luego la tipología de oficios y lugares, para intentar concluir sobre la hermenéutica de las jácaras relacionada con esta figura del mercader.

Palabras clave. Quevedo; jácaras; mercaderes.

Abstract. The author studies here the originality of the figure of the merchant in Quevedo's jácaras. It is perceived first lexicological considerations and also the human relations in this mercantile power; the author makes then an analysis of the typology of offices and spaces, to try to conclude on the sense of the jácaras related to this figure of the merchant.

Keywords. Quevedo; Jácaras; Merchants.

\section{INTRODUCCIÓN}

La representación del poder de los mercaderes en el Siglo de Oro tiene que ver con una visión a la vez histórica y ficcional. Ambos puntos de vista parecen brindarnos representaciones convergentes y divergentes, de las que resulta complicado extraer una visión unánime y conforme a lo que pudo ser la realidad de aquel poder de la economía. 
Disponemos de múltiples textos arbitristas sobre lo que pudo ser la concepción del poder de la economía en los Siglos de Oro. Los arbitristas ${ }^{1}$ afincaron el poder material en el espiritual, como fuente de harmonía sociocultural; de lo contrario, la economía desarticula a la sociedad causando delincuencia, hambruna e inestabilidad política.

¿Pero existió realmente un poder de la economía en el Siglo de Oro, o más bien una forma de malestar en España y su mundo? En palabras de John H. Elliott

hay que considerar la gran crisis de la estructura de la Monarquía en 1640 [...] como desenlace lógico de la crisis económica que destruyó las bases del poder de Castilla, y de la crisis psicológica que la empujó hacia su intento final de conservar la supremacía mundial².

Repetidos fracasos de arbitristas dieron lugar a toda una literatura satíricoburlesca, con representaciones grotescas del poder de la economía, incluso desde el punto de vista del hampa, producto y prueba de la dificultad del príncipe en instaurar prosperidad y felicidad en su reino.

Abundan disparates jocosos sobre aquellos «locos razonadores» 0 «locos repúblicos y de gobierno». Desde El coloquio de los perros o Rinconete y Cortadillo de Miguel de Cervantes, hasta La Fortuna con seso y la hora de todos o el Sueño del infierno se mofa la literatura de esos «arcigogolantes» quevedescos.

Este universo de los «gueux» ${ }^{3}$, detalladamente analizado por $\mathrm{Cros}^{4}$, rebasa de juiciosos estudios que no se trata aquí de repetir. Sin embargo, en la categoría de

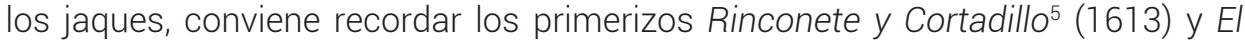

1. Recordemos que las escuelas de Salamanca, Valladolid y Toledo aportaron al arbitrismo las reflexiones de Martín González de Cellorigo con perspectivas de economía interior, Tomás de Mercado con cara a económica internacional, Luis Ortiz con opciones fiscales y monetarias, Sancho Moncada y Pedro Fernández de Navarrete con orientaciones más específicamente mercantilista.

2. Elliott, 2007, p. 297. Por cierto, conscientes de esta crisis económica que azotaba a España, dichos arbitristas fracasaron. Las políticas comerciales, fiscales, monetarias y presupuestarias del CondeDuque de Olivares, como traducción política de los teóricos arbitristas también fracasaron. Padeció además España la disminución de producción mineral del Nuevo Mundo, el declive de la industria, del comercio peninsular, a nivel europeo y mundial -en gran parte debido a la derrota de la Armada Invencible de 1588-. Sufrió incluso las crisis agrarias de los años 1595-1601, sin olvidarse de las oleadas de peste. A este derrumbe económico, hay que sumar el fracaso estratégico del final de la tregua de Doce Años de 1621, la Guerra de los Treinta Años que arranca en 1618 y demás conflictos bélicos que la Unión de la Armas de 1626 no consiguió resolver, generando gastos inmensos, que dejaron a España en manos de sus deudores genoveses y portugueses. Acabando de desmembrar a España, surgen las contiendas locales entre la nobleza y el rey, la fuerte despoblación del país - debido principalmente a la expulsión de los moriscos en 1609-, las oleadas de peste milanesa de 1630 y la mediterránea de 1647, junto con las emigraciones a América por los años 1600-1650, sin hablar de la Revuelta de los catalanes de 1640-1652.

3. Cavillac, 1983.

4. Cros, 1975

5. «y habiendo mi amo avizorado, como en la jácara se dice, si alguien le veía, se entró en una casa» (Cervantes, Rinconete y Cortadillo, p. 329). 
rufián dichoso (1615) de Miguel de Cervantes respectivamente redactados por los años 1600 y 1605, obras a las que añade Pedraza la primera parte del Quijote y La Gitanilla ${ }^{6}$ como primeros atisbos de literatura germanesca.

En aquella Sevilla, teatrum mundi del poder mercantil, seguirá rumbo propio la figura del jaque cervantino, alejándose del molde inicial impulsado por el pícaro del anónimo Lazarillo y retomado luego por Mateo Alemán, aunque con determinados ajustes. De algún modo, también percibe Pedraza rasgos rufianescos en el capítulo V del IV libro de Los trabajos de Persiles y Sigismunda, ya que «en la carta que desde la cárcel romana escribe Bartolomé se recuerda que Quien en mal anda, en mal para; de dos pies, aunque el uno esté sano, si el otro está cojo, tal vez cojea, que las malas compañías no pueden enseñar buenas costumbres». «Se podrían añadir otros juegos intertextuales» precisa Pedraza «pero los señalados bastan [...] para mostrar que la carta de Bartolomé es una original recreación de la jácara. En el Persiles, que Cervantes quiso presentar como un crisol y un centón de los modos y variantes de la literatura de su época, no falta tampoco este género singular»?

En este contexto, las jácaras de Quevedo rebasan de todo un léxico mercantil que ocupa seis de las quince jácaras, dedicadas las demás a los aspectos más formales -actividades mercantiles hampescas, organización, lugares, etc-. Jamás estudiadas desde la perspectiva del poder de los mercaderes, las jácaras nos brindan una representación estética y ética singular sobre esta problemática aurisecular. Si bien los componentes retóricos resultan asequibles desde perspectivas estructurales e intertextuales, el sentido ético presupone mayor precaución debido al subgénero de la jácara, poco propicio a interpretaciones de tipo serio, al contrario de los Sueños, el Buscón o la Hora de todos, siendo para Quevedo la lengua de germanía un campo de investigaciones formales encaminadas hacia la burla antes que la sátira8; ahora bien, el sistema de las auto y heterocitas quevedescas, estudiadas por Fernández Mosquera9 , deja vislumbrar, quizá, y con mucha precaución, algún rasguño, aunque queda excluido hablar de ideología quevedesca desde la jácaras.

Intentaré aquí poner de realce la originalidad de la representación de los mercaderes en las jácaras de Quevedo. Haré hincapié en un primer tiempo en las consideraciones lexicológicas y el tipo de vínculos humanos que presupone este poder mercantil, y veremos luego la tipología de oficios y lugares, para intentar concluir sobre la hermenéutica de las jácaras relacionada con esta figura del mercader: ¿tipo literario positivo o negativo?

6. Ver Pedraza, 2006, p. 80. A pesar de lo interesante de la citada propuesta, conviene no asimilar más allá de los parangones, el ámbito gitano y el caló por una parte con la germanía y su jacaranda por otra parte, debido en particular a diferencias de tipo lingüístico.

7. Pedraza, 2006, p. 86.

8. Arellano, 2003

9. Fernández Mosquera, 2000.

HIPOGRIFO, Volumen extraordinario, 1, 2018 (pp. 233-243) 


\section{EL SUSTRATO LEXICOLÓGICO}

Una aproximación lexicológica permite destacar seis jácaras -la 1, 2, 3, 510 y 15- que rebasan de palabras relacionadas con el ámbito económico y mercantil ${ }^{10}$.

Distintos sustantivos primero como «cuenta» $(\mathrm{J} 1,2)$, «de contado» (J2), «barato» (J3), «plata» (J5), oro (J6), cuarto navarrisco/cuartillo (J15), «moneda» (J2), «limosna» (J5), «censo» (J2), «sin sueldo» (J5), maravedí (J10), «caro» (J10), dinero (J10) y «ahorro» (J10) recorren los señalados poemas.

Funcionan estas redes lexicológicas según un sistema de oposición «barato/ caro», «pagar la patente/sin sueldo», «oro/limosna», sistema identificado por Cros en el Buscón ${ }^{11}$, y que aplicado a las jácaras parece evidenciar disparidades económicas en el mundo del hampa, ámbito que se presenta entonces como una imagen al revés del sistema monetario y económico oficial.

Encontramos luego verbos como «pagar» (J1 y 2), «contribuir» (J1 y 2) o «cobrar» (J10) que enriquecen este léxico mercantil germanesco. Sin embargo, las recurrencias verbales se quedan muy por debajo de los sustantivos, como si el mercantilismo hampesco fuese pasivo más que activo, parecido a un parásito que daña la economía oficial, un peso que hunde la sociedad activa y productiva.

Quevedo poetiza incluso el léxico normativo mediante metáforas burlescas arraigadas en la lengua de germanía, ricamente analizada por Carrei$\mathrm{ra}^{12}$, y que enaltece Quevedo pasándola por el prisma conceptista, declarando en boca de la iza La Perala en la jácara 3 «no la dan, Lampuga, un gozque / si pueden darle un alano» (vv. 21-22), dilogía que explicita Arellano en la nota 69 de su edición ${ }^{13}$ : le dan los patanes a las izas un perro grande -alano- y no uno pequeño - gozque- o sea no le pagan a la ramera, la engañan, inspirándose en la expresión «dar perro muerto».

Por fin, encontramos con orientación paródica, los referentes de la poesía neo-petrarquista como son «perlas» (J5, 6 y 12), «rubíes» (J5 y 12), «aljófar» (J12) o demás «tesoro» (J5), además de figuras retóricas como «darle al Potosí limosna» (jácara 5).

Este variado y paradójico léxico mercantil es indisociable de toda una variedad de actividades hampescas, algunas legales aunque viles, otras ilegales y reprehensibles, cruce que parece inducir como una evolución diegética ${ }^{14}$, desde lo legal y vil hacia lo ilegal conforme nos adentramos en las jácaras, delineándose así algo como un propósito escéptico quevedesco.

\footnotetext{
10. Sigo la edición de Marigno, 2000. Apuntaré «J1» para jácara 1, «J2» para jácara 2, etc.

11. Cros, 1975.

12. Carreira, 2000.

13. Arellano, 2007

14. Se adelanta la idea con pies de plomo, sabiendo la precaución que imponen las cuestiones editoriales del Parnaso español.
} 
No dista tanto la germanía de Quevedo de la realidad, pues el Padre Léon ${ }^{15}$ da cuenta de unos 760 muertos en Sevilla entre 1578 y 1616; aunque falten datos exactos sobre el tema, habría que sumar el número supuestamente elevado de los distintos robos en las diferentes áreas de la germanía, sin descontar la actividad prostibularia, significativamente desarrollada en ciudades con fuerte rumbo económico.

Pero sería lectura errónea considerar la figura del jaque en Quevedo como reflejo de la realidad, cauce por el que parece deslizarse David Becerra Mayor en su intento de «Acercamiento social e ideológico a las jácaras de Quevedo»: «Lo primero que causa extrañamiento es que sea precisamente Quevedo - un escritor organicista- quien muestre -y ceda su voz- a individuos de la clase social más marginal de la sociedad española» ${ }^{16}$.

Una cosa es establecer procedimientos intertextuales entre el subgénero burlesco de la jácara y demás textos de Quevedo, y otra es asimilar la hermenéutica burlesca ficcional de la jácara con la satírica de los Sueños y la Hora de todos o, todavía más discutible, con el de la literatura didáctico moral de Política de Dios por ejemplo. Estos textos no funcionan en el mismo marco formal y mucho menos en idénticos planos ideológicos. Difícil pues compartir el juicio de Becerra Mayor cuando imagina que

Quevedo, pues, retrata en sus jácaras el mundo del hampa con la intención ideológica de denunciar el nuevo orden social, cuya ideología del cambio, no hace sino generar pobreza y caos. Quevedo, de cuyo pensamiento político tenemos constancia gracias a su Política de Dios, gobierno de Cristo y tiranía de Satanás ${ }^{17}$.

Antes de precisar esta variedad mercantil germanesca, conviene apuntar que se trata, en todos los casos, de actividades económicas familiares. Abunda en las jácaras el léxico de la familia con términos como «mamá» (J1), «taita» (J1), el «viejo» (J1), el «padre» (J2, 8 y 9), el «menino» (J2), el «hijo» (J8 y 9). Recordemos que la familia era el tipo de organización mercantil más desarrollada, estrategia que apuntaba a proteger las ganancias propias del monopolio de Estado, que solo se quedaba con el 20\%, o sea, el conocido «quinto real».

En las jácaras sin embargo, la familia cobra un sentido germanesco específico, es decir que los vínculos solo existen aquí en segundo grado, son de tipo jerárquico, su meta consiste en establecer dependencia económica y mercantil, lo cual descarta cualquier relación afectiva como podría suponerlo dicho concepto de «familia». Incluso a muchos huérfanos -recordemos a Rincón, Cortado o los óleos de Murillo y Velázquez- de los que la sociedad ha sido incapaz de hacerse cargo, no les quedaba más remedio que entrar en la germanía para sobrevivir. Recuerda Alonso Hernández que la germanía les proponía a estos desahuciados «la carrera

\footnotetext{
15. Herrera Puga, 1974

16. Becerra Mayor, 2009, p. 189.

17. Becerra Mayor, 2009, p. 189.
} 
completa del maleante» ${ }^{18}$ con progresión de estatutos y grados, aunque encaminado todo esto a la horca.

Los vínculos se vuelven aquí estatutos y los seres mercancías o funciones que se valoran económicamente. El poder económico y mercantil hampesco corresponde con una deshumanización de la persona humana. El recurso estético que permite delinear este mal efecto de una economía mal entendida también la encontramos en La hora de todos, en particular, en boca de la propia Fortuna que viene equiparada con una prostituta que se expresa en lengua de germanía ${ }^{19}$.

\section{LA DIVERSIDAD DEL MERCANTILISMO}

Encontramos muchos oficios legales en las jácaras, desde el «aguador» (J3), hasta la «fregona» (J11), pasando por el «esportillero» (J7). Viles aunque legales, determinados oficios resultan deshonestos, como es engañar poniendo carne humana descuartizada en los conocidos «pasteles de a cuatro» (J3), que también por veces se tornan en «tumbas de «moscas» (J5). El mundo animal sigue animando estas actividades rufianescas deshonradas, como «las ranas que venden en el vino» (J3) los jaques «taberneros en Sevilla» (J7), provocando otras mezclas del vino con agua numerosos ahogos de moscas por culpa de quienes «visten al vino» (J9).

Se van deslizando los rufianes desde lo legal deshonesto hacia lo ilegal reprehensible. Quevedo ilustra todo un abanico de economías ilegales como «santiguador de bolsillos» (J9), «honrador de estaño» (J4), «llavero de cerraduras» (J7), «portero de cofres» (J7), especialista en «dar chirlos a maletas» (J7) y en «juntar diferentes muebles» (J7). Estas fechorías son oficios varoniles que vienen completados por mujeriles actividades como son el «robo de joyas» (J3) en las casas donde se ejerce de fregona (J11) por ejemplo, y, con mayor evidencia, iza o ramera en el «mesón de las ofensas» (J8) también llamado «paradero del vicio» (J9) en que las prostitutas «llevan en una mano las bragas y en otra el caudal» (J15).

Entendemos que, en el ámbito rufianesco, el poder mercantil es una atribución varonil, siendo la fémina una mercancía entre muchas, como por ejemplo los «pollos y quesos desmayados» (J9) o los «pollos desaparecidos» (J4).

Las mercancías robadas (joyas, muebles, alimentos, etc.) se vendían, tildándose así los rufianes de «vendedores a despenseros» (J7). Cabe recalcar esta autoconciencia ficcional del jaque que se autodefine como «vendedor» en la jácara 7 , actividad que considera practicar como un verdadero mercader ya que pretende «campar de mercader» en la misma jácara. El hampa se autodefine siguiendo estatutos oficiales, cuando su meta es ejercer un poder brutal, con lo cual podemos imaginar que el poder de los mercaderes legales y oficiales constaba como una referencia cultural lo suficientemente difundida como para invadir el hampa y ser considerada como referente de dominación y poder. 
Podemos cerrar este listado de mercaderes ilegales con el oficio de fullero (J7), que consistía en robarle cuanto más dinero a los jugadores de tabernas, mediante todo un abanico de «flores» y demás figuras de «langostas que amenazaban el dinero» (J5).

Resulta claro que todas las señaladas actividades de la germanía vienen resumidas, en las jácaras y en boca de los protagonistas, en dos palabras que remiten al ámbito socioeconómico: «vendedor» y «mercader». En el Tesoro de la lengua española o castellana de Sebastián de Covarrubias Horozco ${ }^{20}$ poco lugar ocupa la palabra «vendedor», pero sí el verbo «vender» del que se precisa «que es conmutar la mercanduría u otra cosa por precio cierto y justo». Dicho de otra forma, «vendedor» constaba en aquel momento como actividad y no en tanto que estatuto, con lo cual los jaques podían atribuirse un estatus que al parecer no gozaba de tanto valor en el ámbito sociocultural. Covarrubias relaciona en segundo tiempo «vendedor» con productos relativamente viles como son el vino, la ropa o incluso el engaño, citando expresiones como «vender palabras». En cuanto a «mercader», el Tesoro precisa que se trata del «tratante de mercaderías», sin más añadiduras ni precisiones. Interesante notar que el Diccionario de Autoridades, apunta que mercader es «el que trata o comercia con géneros vendibles», lo cual contamina así la palabra «mercader» debido a los señalados semas despectivos de «vendedor». Añade en este sentido Autoridades que «en la Germanía significaba el ladrón que anda siempre donde hay trato», lo cual confirma Juan Hidalgo ${ }^{21}$.

Por lo visto, el significado de «vendedor» $\mathrm{y}$ «mercader» en las jácaras y en boca de rufianes no parece tan alejado de los significados que se les daba en el contexto académico de la época.

Esta autodefinición como «vendedores» y «mercaderes» procede del lugar donde acontece este poder, es decir, la «Sevilla» que irrumpe todo a lo largo del poemario germanesco y, en concreto, en las jácaras 1, 7 y 8 por ejemplo. La «BabiIonia» andaluza, tal y como se define en la jácara 7 , viene declinada con la ciudad de Granada en la jácara 7.

Esta representación de Sevilla en las jácaras se arraiga en una realidad en que la ciudad era núcleo comercial del Siglo de Oro en tanto que apertura hacia el Imperio de las Indias. En Sevilla se entrecruzaban lo comercial, lo económico, lo financiero y lo humano y, en este contexto, el hampa constaba como una especie de escoria de esta intensidad sevillana. Volviendo a la literatura en general, y más allá de la jácaras, encontramos toda una serie de obras que celebran Sevilla como capital económica, recordemos en especial los gongorinos versos de Las firmezas de Isabela sobre la

gran Babilonia de España,

mapa de todas naciones,

donde el flamenco a su Gante

y el inglés halla a su Londres;

20. Covarrubias Horozco, Tesoro.

21. Hidalgo, 1967. 
escala del Nuevo Mundo,

cuyos ricos escalones,

enladrillados de plata,

son navíos de alto borde 22 .

El Arenal de Sevilla de Lope de Vega celebra con otro estilo esta ciudad theatrum mundi, en bocas de Laura y Urbana:

$\begin{array}{ll}\text { LAURA } & \text { Lo que es más razón que alabes } \\ & \text { es ver salir destas naves } \\ & \text { tanta diversa nación; } \\ & \text { las cosas que desembarcan, } \\ & \text { el salir y entrar en ellas } \\ & \text { y el volver después a ellas } \\ & \text { con otras muchas que embarcan. } \\ & \text { Por cuchillos, el francés, } \\ & \text { mercerías y ruán, } \\ & \text { Ileva aceite; el alemán } \\ & \text { trae lienzo, fustán, llantés..., } \\ & \text { carga vino de Alanís; } \\ & \text { hierro trae el vizcaíno, } \\ & \text { el cuartón, el tiro, el pino; } \\ & \text { el indiano, el ámbar gris, } \\ & \text { la perla, el oro, la plata, } \\ & \text { palo de Campeche, cueros...; } \\ & \text { toda esta arena es dineros. } \\ & \text { Un mundo en cifra retrata. } \\ \text { URBANA } & \text { Los barcos de Gibraltar } \\ \text { LAURA } & \text { traen pescado cada día, } \\ & \text { aunque suele Berbería } \\ \text { URBANA } & \text { algunos dellos pescar. } \\ & \text { Es cosa de admiración } \\ & \text { ver los que vienen y van. } \\ & \text { Los que en el pasaje están } \\ & \text { en grande número son. } \\ \text { URBANA } & \text { la cal, el trigo, hasta el barro }{ }^{23} . \\ & \end{array}$

Historia y fábula entroncan en esta representación de Sevilla como núcleo del poder mercantil. Las jácaras se inspiran en esta misma realidad histórica pero reescriben más allá de los citados palimpsestos gongorino y lopesco cierta idealización del poder de la economía y de los mercaderes como elemento de dicha, prosperidad y riqueza. Siguiendo una estrategia de desmitificación, las jácaras de Quevedo invierten esta visión de magnificencia que recorría toda la literatura seria,

22. Góngora, Las firmezas de Isabela, vv. 488-495.

23. Lope de Vega, El arenal de Sevilla, vv. 22-50. 
para proporcionarle al lector otra vertiente oculta y quizá voluntariamente ignorada del mundo de los banqueros, mercaderes y demás vendedores. Globalmente, Sevilla aparece en Quevedo como un lugar de actividad comercial en particular para taberneros de germanía, cuando las ciudades castellanas -Madrid, Toledo, etc.resultan ser lugares de castigo, como por ejemplo en la jácara 14 en que le ruega la iza Marianilla a su jaque

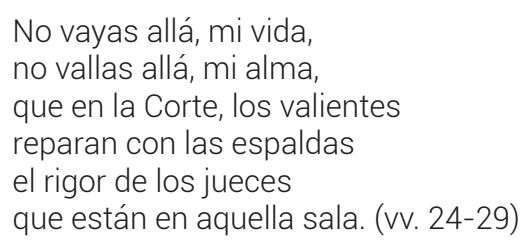

Por cierto, «Sevilla» también cumple con una función puramente literaria que acaba totalmente desconectada de la realidad. Vinculada con nociones temporales, por ejemplo, cumple la función de cronotopo epistolario, particularmente en las jácaras 1 y 2 que le dan la tonalidad general al subgénero de estos romances de germanía.

Otros lugares componen el espacio mercantil del hampa como Toledo, Nápoles en la jácara 8 y Galicia pero más bien como tópicos intertextuales en vez de arquetipos jacarescos específicos como son Sevilla -capital económica- o Madrid - capital jurídicas y política-. La capital política, parece mantener en Quevedo la función de estabilidad moral y política de la que Sevilla parece haberse olvidado, quizá debido a tanto banquero, mercader y demás vendedores que parecen haberse vuelto los verdaderos administradores de tantas riquezas.

\section{CONCLUSIONES}

Desde una perspectiva lexicológica y diegética, además de aproximaciones intertextuales e históricas, he propuesto una interpretación decadente del jaque desde actividades mercantiles viles pero legales -en un primer tiempo- hacia otras ilegales y encaminadas a los conocidos azotes, galeras o «ene de palo»-en un segundo tiempo-. Este recorrido biográfico decadente del jaque causado / relacionado con temáticas mercantiles, nos conduce a concluir sobre una representación negativa de todo aquello que viene vinculado con banqueros, mercaderes y vendedores en la jácaras de Quevedo.

La dificultad en la hermenéutica de este recorrido decadente, que lleva a estos jaques desde la Babilonia donde practican un relativo poder de mercaderes / vendedores, hacia la Corte donde la justicia ejerce en estos rufianes sus despiadados castigos, prueba de ello el llanto de una iza en la jácara 2 según quien

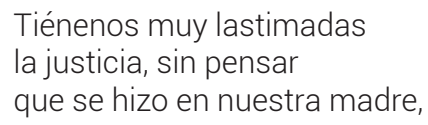




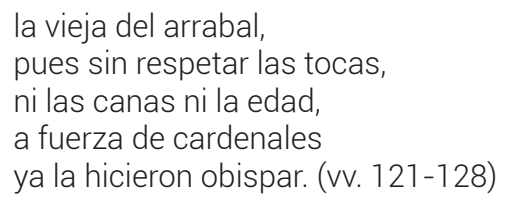

¿Son las jácaras una advertencia acerca de lo que podría ser un poder económico y mercantil mal entendido? ¿Son las jácaras una representación al revés del poder del dinero mal invertido, una forma de rasguño al egocentrismo capitalista? ${ }^{24}$ Es difícil descartar esta posibilidad pero, el género de estos textos y su impacto, nos llevan a relativizar el valor que le quiso dar Quevedo y el eco que pudo tener este eventual discurso en el receptor.

Menos polémico quizá desde una perspectiva estilística, el hecho de que Quevedo trasvasó al Buscón la lógica conceptista anteriormente afincada en la poesía, para luego alzar la lengua de la germanía hacia la agudeza poética tal y como lo analizó Chevalier ${ }^{25}$. Prueba de ello, los múltiples ejemplos contrafactum de lo divino que vinieron a continuación.

En todo caso, los mercaderes hampescos de Quevedo constan como una representación poética única del poder de los mercaderes en la centuria del XVII español, un arquetipo original en el panorama general de la picaresca y germanía.

Cervantes humanizó mediante Rincón y Cortado a estos prototipos literarios, declarando al propósito Pedraza que

Cervantes nos brinda quizá una representación más realista y menos poética que la de Quevedo: la prosa cervantina, pese a su belleza, serenidad y equilibrio, se presenta a los ojos del lector como el cristal trasparente que le permite ver fielmente el mundo exterior ${ }^{26}$.

Sin embargo, donde Cervantes humaniza, Quevedo infunde una forma de escepticismo hermenéutico que, a falta de alcanzar un discurso ideológico claro, suscita un sentimiento de pesadilla, un sueño infernal, ¿cómo resultado de un poder económico descontrolado?

\section{BIBLIOGRAFÍA}

Alonso Hernández, José Luis, Léxico del marginalismo, Salamanca, Universidad de Salamanca, 1977.

Arellano, Ignacio, Francisco de Quevedo. Poesía burlesca. Tomo II: Jácaras y Bailes, Alicante, Biblioteca Virtual Miguel de Cervantes, 2007. Disponible en línea: <http://www.cervantesvirtual.com/obra/poesia-burlesca-tomo-ii-jacaras-ybailes--0/> [16/01/2017]. 
Arellano, Ignacio, Poesía satírico-burlesca de Quevedo, Madrid, Iberoamericana Vervuert, 2003.

Becerra Mayor, David, «Acercamiento social e ideológico a las jácaras de Quevedo. Carta de Escarramán a la Méndez», La Perinola, 13, 2009, pp. 183-208.

Carreira, Antonio, «El conceptismo en las jácaras de Quevedo: "Estábase el Padre Esquerra"», La Perinola, 4, 2000, pp. 91-106.

Cavillac, Michel, Gueux et marchands dans le «Guzmán de Alfarache» (1599-1604): roman picaresque et mentalité bourgeoise dans l'Espagne du Siècle d'Or, Bordeaux, Institut d'Etudes Ibériques et Ibero-Américaines de I'Université, 1983.

Cervantes y Saavedra, Miguel de, Novelas ejemplares, Madrid, Cátedra, 1994.

Chevalier, Maxime, Quevedo y su tiempo: la agudeza verbal, Barcelona, Crítica, 1992.

Covarrubias Horozco, Sebastián de, Tesoro de la lengua castellana o española, ed. Ignacio Arellano y Rafael Zafra, Madrid, Iberoamericana/Vervuert, 2006.

Cros, Edmond, L'aristocrate et le Carnaval des Gueux. Étude sur le «Buscón» de Quevedo, Montpellier, CERSC, 1975.

Elliott, John H., España y su mundo (1500-1700), Madrid, Taurus, 2007.

Fernández Mosquera, Santiago, «La hora de la reescritura en Quevedo», Criticón, 79, 2000, pp. 65-86.

Geisler, Eberhard, El dinero en la obra de Quevedo. La crisis de identidad en la sociedad feudal española a principios del siglo XVII, Kassel, Reichenberger, 2013.

Góngora y Argote, Luis de, Las firmezas de Isabela, ed. Robert Jammes, Madrid, Castalia, 1984.

Herrera Puga, Pedro, Sociedad y delincuencia en el Siglo de Oro, Madrid, BAC, 1974.

Hidalgo, Juan, Romancero de germanía, Madrid, Taurus, 1967.

Marigno, Emmanuel, Francisco de Quevedo. Jácaras, Lille, Septentrion, 2000.

Vega y Carpio, Lope de, El Arenal de Sevilla, ed. Manuel Cornejo, en Comedias de Lope de Vega. Parte XI, dir. Laura Fernández y Gonzalo Pontón, Madrid, Gredos, 2012, 2 vols, pp. 459-610.

VV. AA., Edad de oro Cantabrigense. Actas del VII Congreso de la Asociación Internacional Siglo de Oro, dir. Anthony Close, Madrid, Iberoamericana/Vervuert, 2006. 
